\title{
Pharmacogenomics; From the UK to global populations
}

Emma Magavern ${ }^{1}$, Ann Daly ${ }^{2}$, Annette Gilchrist ${ }^{3}$, and Dyfrig Hughes ${ }^{4}$

${ }^{1}$ Barts and The London School of Medicine and Dentistry

${ }^{2}$ Newcastle University

${ }^{3}$ Midwestern University Chicago College of Pharmacy

${ }^{4}$ Bangor University

March 24, 2021

Hosted file

BJCP spotlight commentary PGx March 23.pdf available at https://authorea.com/users/403827/

articles/515181-pharmacogenomics-from-the-uk-to-global-populations 